\title{
Objetos indígenas: do artificial ao
}

\section{imaterial}

\author{
Indian objects: from artificial to the intangible
}

\author{
Analucia Thompson*
}

RESUMO

Analisamos neste artigo os diversos sentidos que foram atribuídos aos objetos indígenas ao longo da trajetória de constituição dos museus modernos, para, então, tecer algumas considerações sobre os significados atribuídos a eles nas concepções de patrimônio cultural desenvolvidas pelas políticas públicas preservacionistas, especificamente pelo Instituto do Patrimônio Histórico e Artístico Nacional. Partimos do princípio que os museus se constituíram como os lugares privilegiados de guarda desses objetos, expressando assim as ações, as práticas sociais, as técnicas e o modo como o conhecimento foi e é construído e reproduzido sobre aquilo que se encontra em museus. A análise das significações e as ressignificações de 'coisas' que passam a ser denominadas em determinado momento etnográficas, permite desnaturalizar a concepção de que os objetos existem por si só como, por exemplo, etnográficos ou artísticos. Desenvolvemos, nesse sentido, uma historicização do processo de musealização dos objetos indígenas para entender as conformações que hoje adquire a patrimonialização de bens culturais de grupos indígenas.

Palavras-chave: Antropologia. Patrimônio cultural. Museus. Coleções etnográficas. Objetos indígenas.

\section{ABSTRACT}

In this article, we analyze the various meanings ascribed to indigenous objects along the trajectory of the constitution of modern museums, and then we present some considerations on the meanings assigned to

\footnotetext{
* Doutora em Museologia, técnica pesquisadora do Instituto do Patrimônio Histórico e Artístico Nacional e professora do Curso de Mestrado Profissional em Preservação do Patrimônio Cultural do IPHAN.
} 
them in conceptions of cultural heritage preservationists developed by public policy, specifically by the Instituto do Patrimônio Histórico e Artístico Nacional. We assume that museums were formed as a privileged site of custody of Indian objects, thus expressing the actions, the social practices, the techniques, and the way knowledge used to be and still is constructed and reproduced on items brought to museums. The analysis of meanings and reinterpretations of 'things', that are denominated in certain moments as ethnographic allow deconstruct the idea that objects exist by itself, for example, ethnographic or artistic. We develop, in this sense, an analysis that historicizes process of musealization indigenous objects to understand the shape that nowadays the patrimony of cultural goods of indigenous groups acquires.

Keyword: Anthropology. Cultural heritage. Museums. Ethnographic collections. Indigenous objects.

O colecionismo de objetos ${ }^{1}$ indígenas tem uma longa história, pelo menos, desde quando os nativos de regiões que sofreram o processo de colonização europeia foram batizados de índios.

Os viajantes europeus da era dos descobrimentos levavam para seus países, além de ouro e prata, subprodutos exóticos fabricados por grupos nativos da América, Ásia e África, destinados aos gabinetes de curiosidades que se tornaram, nos séculos XVI e XVII, 'moda' entre nobres, burgueses ricos e papas (ALEXANDER; ALEXANDER, 2008; POSSAS, 2005). No século XVIII, esses objetos, assim como os espécimes naturais, começaram a ser submetidos a procedimentos sistemáticos de pesquisa. Com a constituição dos museus de etnologia no final do século XIX, os objetos indígenas passaram a ser definidos segundo preceitos científicos, que buscavam atestar o lugar que esses povos ocupavam na evolução da humanidade (BENNETT, 2009; SHELTON, 2011). No século XX, após o processo de descolonização, principalmente a partir dos anos 1960, surgiram dúvidas sobre as funções desses objetos guardados em museus e sobre o caráter educativo dos museus de etnologia (HARMS, 1990; SHELTON, 2011), que somadas à ampliação da concepção de patrimônio cultural, assistiram a emergência de movimentos constituídos por grupos indígenas que reivindicavam a propriedade de seus bens culturais.

Os museus se estabeleceram, assim, como os lugares privilegiados de guarda desses objetos. As diversas denominações atribuídas a eles ao longo desses séculos expressam as ações, as práticas sociais, as técnicas e o modo como o conhecimento foi e é construído e reproduzido (SMITH, 2006) sobre os objetos levados para museus. A análise das significações e as ressignificações de 'coisas' que passam a ser denominadas em determinado momento etnográficas permite desnaturalizar a concepção de que os objetos

\footnotetext{
${ }^{1}$ Usamos o termo objeto aqui no seu sentido mais elementar, ou seja, como designando aquilo que está colocado à frente de um sujeito, o qual, por sua vez, o trata como algo diferente de si próprio (DESVALLEES; MAIRESSE, 2011).
} 
existem por si só como, por exemplo, etnográficos ou artísticos. Essas são categorias criadas para designar 'coisas' que circulam, são exibidas e consumidas.

Analisamos neste artigo os diversos sentidos que foram atribuídos aos objetos indígenas ao longo da trajetória da constituição dos museus modernos, para, então, concluir com algumas considerações sobre os significados conferidos a eles nas concepções e práticas desenvolvidas pela política pública preservacionista do Instituto do Patrimônio Histórico e Artístico Nacional. Desenvolvemos, nesse sentido, uma análise que historiciza o processo de musealização dos objetos indígenas para entender as conformações que hoje adquire a patrimonialização de bens culturais de grupos indígenas.

\section{Objetos Artificialia}

Os objetos e espécimes acumulados nos gabinetes de curiosidades dos séculos XVI e XVII eram classificados em Naturalia e Mirabilia. Ao primeiro termo correspondiam os exemplares dos reinos animal, vegetal e mineral. O segundo compreendia as coleções inseridas em dois conjuntos: Artificialia e Antiquas. Os exemplares produzidos pelo homem, que mais tarde seriam chamados de objetos etnográficos, em oposição aos adquiridos no âmbito da natureza, compunham a Artificialia; os objetos oriundos da Antiguidade Clássica, a Antiquas (POSSAS, 2005).

Na seção Artificialia, os inventos humanos colecionados iam de armas a objetos exóticos de diversas culturas trazidos por viajantes. As coleções eram caracterizadas pela aleatoriedade da disposição dos exemplares, e seu tamanho designava o prestígio do colecionador. Se, por um lado, não podemos encontrar uma ordem clara e definida por critérios objetivos na disposição dos objetos nessas coleções, por outro lado, podemos perceber que eles estavam inseridos em uma ordenação típica do período renascentista, tomada emprestada da escolástica medieval, que partia da premissa de que havia um significado inato nas coisas, dado pela natureza da revelação: um macrocosmo que podia ser representado em um microcosmo (SHELTON, 1997, p. 181). A crença de que havia entre o macrocosmo e o microcosmo uma relação de correspondência conferia aos objetos de uma coleção a capacidade de reprodução de todos os aspectos do mundo mais amplo. Esse microcosmo, representado nas coleções dos gabinetes reais e imperiais, simulava a ideia de que esse universo estava submetido ao poder desses governantes (DACOSTA KAUFMANN, 1997).

Segundo Shelton (1997), as categorias de maravilha e de paganismo foram significativas para o entendimento pelos europeus da novidade que foi a América. $\mathrm{O}$ maravilhoso era entendido por suas reputações miraculosas e mágicas que eram manifestadas nos objetos colecionados, seja pelo tipo de material precioso utilizado, seja pela qualidade do trabalho 
realizado. Os objetos indígenas serviam como testemunhas da afirmação de paganismo, categoria amplamente utilizada, ao longo do período renascentista, na classificação dos habitantes do Novo Mundo. O objetivo do discurso teológico era incorporar e domesticar a presença de um mundo novo potencialmente transgressivo.

Os artefatos indígenas americanos mais valorizados pelos europeus eram os confeccionados com penas, pois eram vistos como representações das capacidades humanas de destreza, ao combinar corretamente os elementos da composição, a luz e a cor, de forma a corresponder fielmente ao real, conforme determinava a estética medieval.

A partir do século XVII, começaram a surgir, nos gabinetes de curiosidades, processos voltados para a ordenação das coleções. A possibilidade de classificação passou a transformar esses gabinetes em lugares destinados a estudos ligados à especialização de novos domínios do conhecimento. "Tratava-se, então, de proporcionar aos estudiosos uma viagem ao mundo desconhecido sem o deslocamento físico" (POSSAS, 2005, p. 157), levando os antigos colecionadores a se tornarem especialistas em ramos da história natural.

\section{Objetos Espécimes}

Dos dois setores inseridos nos gabinetes de curiosidades Artificialia e Naturalia, este último, relacionado aos espécimes naturais, foi o que primeiro adquiriu, no século XVIII, autonomia com o desenvolvimento dos gabinetes de história natural, ao mesmo tempo em que ocorria a formação desse campo de conhecimento.

A constituição do campo da história natural está relacionada ao sueco Carolus Linnaeus (1707-1778), ou simplesmente Lineu, que ao propor uma nomenclatura baseada em classes, ordens, gêneros e espécies para a classificação dos seres vivos difundiu um método que passou a definir uma nova categoria de pesquisadores. O termo 'naturalistas' passou a qualificar os viajantes que buscavam novas descobertas; e as excursões exploratórias passaram a ser rotuladas de científicas. O escrito Systema Naturae de Lineu assemelhava-se a uma obra aberta, que deveria ser constantemente renovada com novos achados oriundos de regiões, cuja natureza ainda não havia sido 'cientificamente' classificada. As viagens exploratórias do século XVIII, voltadas para a descoberta de novos espécimes, que deveriam ser classificados no sistema natural de Lineu, representavam mudanças epistemológicas baseadas na intenção de uma descrição completa da natureza e de sua classificação racional. Nessa descrição, deveriam ser detalhados o modo de vida dos outros povos e de suas culturas, destacando o ambiente, o clima, a flora e a fauna, as plantas comestíveis, os minerais, a quantidade da população, a aparência externa do povo, a língua, as formas de moradia, o uso de armas e ferramentas, a alimentação e o vestiário, como também a visão religiosa do mundo, a organização jurídica, as formas de organização política, as 
modalidades de relações de troca e comércio (BOURGUET, 1997); ou seja, deveria ser composta uma obra enciclopédica do mundo.

Segundo Thomas (1997), que analisa 'as curiosidades artificiais' levadas para a Europa pelas expedições de James Cook, ocorridas entre 1768 e 1780, e as representações desses objetos nas publicações sobre essas viagens, as formas impressas desses objetos foram responsáveis por gerar, ao longo do século XIX, uma tradição baseada na representação descontextualizada das imagens desses artefatos, que persistiu com a fotografia ao longo do século XX. Essas publicações de viagens eram bastante populares no final do século XVIII, e um dos motivos para isso pode ser explicado pela ideia de curiosidade que estava sendo acionada por meio dessas gravuras.

O significado de 'curioso' tem uma trajetória ambígua, não tendo tido sempre o mesmo conteúdo. Como afirmamos acima, ao longo do século XVI e XVII, o 'curioso' foi associado ao maravilhoso e ao paganismo; já no século XIX, seu significado estava mais próximo das manifestações de idolatria ou de canibalismo (THOMAS, 1997). Na segunda metade do século XVIII, as gravuras apresentadas nos livros sobre as viagens de James Cook, que mostravam objetos indígenas, seguiam as convenções das ilustrações da história natural, associando artefatos a espécimes.

Thomas analisa as gravuras que retratavam os objetos dos nativos da Austrália e as compara com outras gravuras presentes nas mesmas publicações que representavam os europeus participantes das viagens. Nesse segundo caso, era efetuada uma contextualização histórica, exemplificada pelas vestimentas, os móveis e outros elementos que indicavam não somente a origem europeia, mas também a posição social do sujeito. A essa imagem era incorporada uma representação de algum espécime natural, como, por exemplo, uma planta pertencente à região visitada; nesse caso, fora de contexto. No que diz respeito aos artefatos, as gravuras traziam agrupados diferentes tipos de objetos - ornamentos, armas, utensílios sem explicação ou qualquer contextualização. Da mesma forma que os espécimes estavam fora de contexto ao serem associados a ambientes europeus, a representação dos objetos indígenas seguia a mesma orientação. É nesse sentido que Thomas afirma que essas ilustrações estavam sendo realizadas a partir de modelos da história natural, pois esses objetos não estavam submetidos a nenhum discurso teórico ou a uma pesquisa sistemática, não eram associados às classificações de Lineu, que não podiam ser aplicadas a artefatos, como também não estavam relacionados a estudos comparativos de tecnologia e arte. Eles não exerceram nenhuma parte significativa no projeto etnológico de discriminação e avaliação da promoção dos vários povos com os quais houve contato; eram espécimes, porque assim eram tratados (THOMAS, 1997, p. 132-133).

Esse tipo de tratamento, que dispunha esses objetos no espaço dos espécimes, não se devia, entretanto, somente à ausência de um sistema classificatório para os artefatos 
indígenas; trazia implícito o objetivo de dissociá-los dos interesses comerciais, políticos e individuais que estavam presentes em sua aquisição.

Insere-se nesse contexto a Casa de Xavier dos Pássaros, aberta em 1784 no Rio de Janeiro, considerada o primeiro museu do Brasil. Funcionou como um entreposto, onde produtos naturais e adornos indígenas eram colecionados, armazenados e preparados para em seguida serem enviados para Portugal (LOPES, 1997).

\section{Objeto primitivo: selvagem e domesticado}

Após as viagens geográficas do século XVIII que delinearam o mapa do mundo, marcando a última fase marítima da exploração europeia, uma nova perspectiva passou a definir as viagens científicas, que, no início do século XIX, se orientavam para a exploração do interior dos continentes.

Segundo Pratt (1991), esses viajantes poderiam ser denominados exploradoresescritores, tendo sido responsáveis por uma verdadeira invasão da África e da América no final do século XVIII e na primeira metade do XIX. No caso da América, o expoente de grupo foi Alexander von Humboldt, que entre 1799 e 1804, realizou viagens pela América do Sul e Central, não conseguindo entrar em território brasileiro por impedimento das autoridades portuguesas.

Embora subordinados aos espécimes naturais, nessa primeira metade do século XIX, já era possível perceber um interesse diferenciado nos objetos de grupos indígenas. ${ }^{2}$

Essa consideração não está somente baseada na aquisição deliberada de objetos reconhecidos hoje como etnográficos, mas também na influência exercida pelo Romantismo alemão na concepção de cultura, ao destacar as particularidades dos costumes, das crenças, das manifestações e dos próprios artefatos de cada povo.

O ambiente epistemológico que predominou no final do século XVIII e na primeira metade do século XIX pode ser considerado como caracterizado por dois movimentos paralelos, que, às vezes, divergiam e, em outras, convergiam e até mesclavam-se: o projeto

\footnotetext{
${ }^{2}$ Meu interesse nesse tema é originado da pesquisa desenvolvida no doutorado em Museologia sobre a Coleção Natterer (THOMPSON, 2012), considerada a maior coleção do mundo fora do Brasil composta de objetos etnográficos de indígenas do território brasileiro, com cerca de 2400 peças. Seu processo de colecionamento foi realizado no contexto da Missão Austríaca, cujos integrantes percorreram grande parte do território brasileiro entre 1817 e 1835. A Coleção se encontra no Museu de Etnologia de Viena, que mudou sua denominação, em 2013, para Museu do Mundo de Viena. É nesse sentido, também, que devem ser entendidas, neste artigo, as referências aos museus de língua alemã.
} 
iluminista e o projeto romântico. Se por um lado, o projeto iluminista se voltava para a coleta, a classificação, a sistematização e a comparação do maior volume possível de conhecimentos, tido como necessários para a promoção do avanço da razão, do progresso, da ciência e da tecnologia, por outro, o projeto romântico, que deslocava a atenção iluminista sobre o indivíduo para o grupo, da razão para a emoção, buscava compreender as particularidades culturais.

Nesse processo, o projeto romântico exerceu um papel político importante, ao afirmar o caráter particular e singular de cada povo, expresso em seus costumes, valores, língua e 'espírito' - Volksgeist - e desempenhou também a possibilidade de uma nova perspectiva cognitiva em relação ao potencial que o conhecimento adquirido sobre o povo poderia proporcionar.

Baseados no conceito de Volk, principalmente do escritor alemão Johann Gottfried von Herder, desenvolveram-se estudos empíricos, que se propunham a coletar informações sobre os costumes camponeses, vistos como os representantes do verdadeiro 'espírito' do povo, pois suas origens eram identificadas como míticas e tradicionais. Esses estudos passaram a ser denominados Volkskunde, ou seja, conhecimento sobre o povo, cujo objeto era constituído por lendas, contos, vestuário, dança, ofício, habilidades etc. Com a expansão desses estudos para fora da Europa, o conhecimento sobre o povo, tornou-se o conhecimento sobre os povos - Völkerkunde -, ou o conhecimento sobre os povos remotos (ERIKSEN; NIELSEN, 2001; PENNY, 2002).

Essa nova perspectiva adicionada pelo Romantismo refletiu-se também na classificação dos artefatos indígenas, que passaram a ser distanciados dos espécimes. A concepção romântica de valorização das particularidades culturais, a coleta intencional e quantitativamente significativa de objetos de outras culturas apontam para essa diferenciação.

Sabemos que a disciplinarização da antropologia ocorreu na segunda metade do século XIX, iniciada nos museus de países de língua alemã (PENNY, 2002; SHELTON, 2011), e que, após as viagens de Charles Darwin, foi muito influenciada pelo evolucionismo. Nessa primeira metade desse século, porém, alguns pressupostos que iriam marcar a disciplina já estavam sendo praticados: como o uso do diário, para registrar informações e observações particulares; a busca do contato com as populações nativas, decorrente da interiorização das expedições científicas; o acúmulo de objetos indígenas colecionados; além do reconhecimento por parte dos colecionadores de que esses objetos tinham valor para seus proprietários originais (THOMPSON, 2012).

Se a categoria de etnográfico ainda não pode ser claramente definida para esse período, pois ainda está incompleto o processo de disciplinarização da antropologia, como um campo de conhecimento autônomo que se constitui como um saber disciplinar e que define seu 
objeto como 'etnográfico', que sentidos eram atribuidos aos objetos indígenas por seus colecionadores?

O método e a terminologia da história natural serviam como modelo para a antropologia física, cujo expoente nos países de língua alemã era Johann Friedrich Blumenbach, que havia estabelecido a premissa dos estudos de crânios humanos, os quais deveriam ser analisados como as outras espécies do reino animal, imparcialmente; a comparação deveria ser feita com corpos humanos, buscando similaridades e diferenças em diversas partes do mundo (ROQUE, 2010). A história natural constituía-se, assim, como um campo de conhecimento multidisciplinar, para usar um termo atual, pois não podia ser "compreendida como uma especialidade desvinculada das demais ciências. História, filosofia, estética e antropologia concorrem para dar legitimidade à totalidade dos fenômenos observados." (KURY, 2001, p. 64).

Nesse momento que antecede a classificação dos objetos indígenas como etnográficos podemos perceber que os artefatos coletados eram vistos por seus colecionadores como representando o 'primitivo', complementado com as qualificações 'selvagem' ou 'manso/domesticado', portanto, ainda submetidos à terminologia da história natural destinada aos animais de uma forma geral. É, nesse sentido, que muitos naturalistas desse período demonstravam interesse em adquirir crânios de humanos, e não somente artefatos. ${ }^{3}$ Apenas na segunda metade do século XIX, esses objetos seriam significados como objetos 'culturais', 'artísticos' ou 'etnográficos (COUTO, 2007).

Corresponde a esse período a criação do Museu Real por Dom João VI em 1818, que reproduziu "o modelo museológico vigente no mundo europeu" e cujo acervo foi "acrescido das contribuições dos naturalistas que viajaram pelo Brasil: Langsdoff, Natterer, Von Martius, Von Spix e outros." (CHAGAS, 1998, p. 31-32).

\section{Objetos Etnográficos}

A partir da segunda metade do século XIX, começaram a ser formados dentro dos gabinetes de história natural os departamentos de antropologia ou etnografia, retratando o processo de especialização desse campo nos museus. Como afirma Shelton (2011), a antropologia, principalmente nos países de língua alemã, foi primeiro estabelecida em museus, para mais tarde se constituir um campo acadêmico.

\footnotetext{
${ }^{3}$ Quando o príncipe Maximilian von Wied-Neuwied retornou de sua expedição ao Brasil, que ocorreu entre 1815 e 1817, levou consigo um crânio de um índio Botocudo, que foi classificado por Blumenbach como situado "a meio caminho entre o orangotango e o homem" (CUNHA, 1998, p. 134).
} 
No âmbito dos museus, os objetos passavam a ser denominados etnográficos a partir de um processo de especialização que se orientava, ainda seguindo o modelo da história natural, no sentido de especificar as coleções antropológicas, dividindo-as em três grupos: a coleção antropológica em sentido estrito, composta por crânios e esqueletos de raças; a coleção pré-histórica, composta por objetos arqueológicos; e a coleção etnográfica referente aos objetos produzidos por grupos humanos contemporâneos e considerados 'primitivos' (HEGER, 1908).

Nesse processo, Adolf Bastian, professor de Etnologia da Universidade de Berlim, fundador do Museu de Etnologia de Berlim e seu diretor entre 1873 e 1905, exerceu um papel significativo não só na formação dos museus de etnologia como também na linha culturalista da antropologia que se tornou predominante não só nos países de língua alemã, como também nos Estados Unidos por influência de Franz Boas, que havia estudado com Bastian (PENNY, 2002). Também no Brasil, essa linha prevaleceu ao longo do século XIX e no início do século $\mathrm{XX}$, quando diversos viajantes de origem alemã estiveram no país, estudando grupos indígenas (GRUPIONI, 1998).

Segundo Penny (2002), que estudou os museus alemães de etnologia da segunda metade do século XIX, havia um projeto etnográfico nessas instituições que possibilitou que elas se tornassem, naquele momento, mais robustas do que as britânicas, apesar da diferença de poder colonialista entre os dois impérios. Esse projeto assentava-se na tradição humanista liberal germânica e na intenção de travar contato com povos não europeus e foi inicialmente concebido por Bastian, que partia do princípio de que todas as culturas têm uma origem comum, da qual se ramificariam em várias direções. Essas variações só podiam ser analisadas no contexto dos museus, onde era possível realizar a associação dos diferentes traços empíricos da história humana para posteriores generalizações e confirmações de teorias (PENNY, 2002).

As coleções etnográficas, seus sistemas de classificação e suas formas de exposição precederam os museus de etnologia. Nesse sentido, os termos etnografia e etnologia eram usados de forma intercambiável, ambos referindo-se à descrição e à comparação de culturas e povos, mas distinguindo-se da antropologia física e da arqueologia.

Para o antropólogo francês Lévi-Strauss (1975), fora as acepções regionais ou nacionais, os termos etnografia, etnologia e antropologia fazem referência a etapas de uma mesma investigação. A etnografia estaria mais voltada para o trabalho de campo, em que a observação, a descrição e os métodos adotados para a classificação e para a análise dos "fenômenos culturais particulares", quando relacionadas aos objetos materiais, são operações que "prosseguem geralmente no museu, que pode ser considerado, sob este aspecto, como um prolongamento do campo" (LÉVI-STRAUSS, 1975, p. 395). A etnologia corresponderia, em relação à etnografia, a um primeiro movimento em direção à síntese, constituindo-se em um conhecimento a posteriori, um prolongamento da etnografia. 
Os objetos etnográficos passaram a significar as coleções abrigadas em tipos específicos de museus, denominados museus de etnologia, de antropologia ou etnográfico. Segundo Harms (1990) o termo 'museu de etnologia', distinto do 'museu etnográfico', o qual inclui também museus regionais de história social e cultural em todo mundo (HARMS, 1990, p. 475), traduz de forma mais precisa os museus que expõem os objetos materiais de 'outras' culturas.

Se por um lado, a tradição bastianiana buscou enfatizar a singularidade de cada cultura, ressaltando o relativismo cultural e a adoção do método comparativo em um sentido analítico, por outro, a teoria evolucionista que era, na segunda metade do século XIX, favorecida pela experiência do colonialismo e pela influência das ideias propaladas por Charles Darwin, encontrava ressonância em antropólogos britânicos como Edward Burnett Tylor e James George Frazer: "para Tylor e outros evolucionistas vitorianos a humanidade consistia em grupos que eram aculturados em vários graus e distribuídos nos degraus de uma escada de evolução cultural" (ERIKSEN, NIELSEN, 2001, p. 36).

Esse período de especialização dos museus de etnologia, antropologia e etnografia corresponde ao que Peirano (1999) denomina de "alteridade radical" para a relação que a antropologia estipulava entre o sujeito e seu objeto, cujos preceitos estavam baseados na concepção evolucionista e no estudo de povos exóticos e distantes. Nesse momento, os objetos etnográficos coletados em campo tinham a função de atestar, por meio da cultura material, o caráter primitivo de povos contemporâneos, a partir de classificações e arranjos das coleções, que, seguindo critérios geográficos, como África, Ásia, América, afirmavam a superioridade da Europa (CHAPMAN, 1985, STURGE, 2003).

A distinção entre os termos antropologia social, usado por anglo-saxões, e antropologia cultural, corrente entre os norte-americanos, está ligada à própria história da disciplina e a suas perspectivas teóricas sobre o papel dos objetos etnográficos. A tradição inglesa, principalmente a do antropólogo Radcliffe-Brown, determinou como objeto de pesquisa da antropologia as relações sociais e a estrutura social, enfocando o grupo em primeiro plano. Já a linha norte-americana definiu as técnicas como ponto de partida para, então, chegar às relações sociais. Assim, a 'escola' norte-americana parte

[...] das técnicas e objetos para terminar nesta 'supertécnica' que é a atividade social e política, tornando possível e condicionando a vida em sociedade, a outra [a 'escola' inglesa] partindo da vida social para descer até as coisas nas quais ela imprime sua marca, e até as atividades através das quais ela se manifesta (LÉVI-STRAUSS, 1975, p. 398). 
Nesse sentido, a antropologia, seja cultural ou social, visa a conhecer o "homem total, encarado, num caso, a partir de suas produções; no outro, a partir de suas representações" (LÉVI-STRAUSS, 1975, p.399). Essa distinção teria ainda uma correspondência com a evolução da sociologia na França, baseada em Émile Durkheim, que, ao definir os fatos sociais como 'coisas', estaria mais próximo da antropologia cultural; enquanto Marcel Mauss e Bronislaw Malinowski complementavam a definição durkheimiana, afirmando que as 'coisas' são elas mesmas fatos sociais, e, dessa forma, estariam mais alinhados à antropologia social.

Embora o papel dos objetos etnográficos tenha sido definido teórica $\mathrm{e}$ metodologicamente pelas vertentes da antropologia acadêmica no final do século XIX, no século seguinte continuaram sendo alocadas coleções formadas por artefatos de grupos indígenas nos museus. Nesse momento, a função social e a histórica dessas instituições passavam a ser destacadas como lugares de registro da cultura material de povos ameaçados de desaparecer ou de perder seus traços culturais originais. O Museu do Homem francês, estabelecido em 1937, foi considerado a principal inovação nesse período (ALEXANDER; ALEXANDER, 2008; CAVIGNAC, 2011; L'ESTOILE, 2003). A concepção que marcou sua fundação foi formulada por Paul Rivet, por Georges-Henri Rivière e por Jacques Soustelle e sustentava-se na crença na existência de uma humanidade indivisível no tempo e no espaço, formada por uma diversidade de culturas. $O$ museu, nesse sentido, devia constituir-se como um laboratório de etnografia, onde os objetos culturais poderiam ser visualizados, para posterior teorização antropológica ou etnológica (CAVIGNAC, 2011).

No Brasil a experiência do Museu do Homem influenciou a criação do Museu do Índio, fundado em 1953 pelo antropólogo Darcy Ribeiro, cujo projeto se destinava a "mostrar a unidade da espécie humana em sua diversidade cultural" e, seguindo as formulações do antropólogo norte-americano Franz Boas, a apresentar uma "antropologia que buscava contextualizar os objetos, atribuindo a eles uma visão etnográfica” (ABREU, 2007, p. 150). A função dos museus, vista dessa perspectiva, tornava-se fundamentalmente pedagógica e política e tinha a finalidade de lutar contra os preconceitos relativos aos povos 'primitivos', o que seria alcançado por meio do conhecimento mútuo entre as culturas. Além disso, acreditava-se que o futuro desses grupos era o desaparecimento, de forma que seus bens materiais estariam preservados em museus, que os guardariam, conservariam e divulgariam.

Essa mesma orientação guiou os museus etnológicos de países de língua alemã nesse período (HARMS, 1990). Constituía-se, na realidade, como uma saída para trabalhar com coleções que haviam sido formadas no contexto violento do colonialismo. Após 1946, em diversos encontros promovidos por museólogos de museus de língua alemã, as questões centrais nessas discussões diziam respeito aos objetivos e finalidades dos museus de etnologia. Ao longo desses anos - Harms analisa esse tema até a década de 1980 -, várias ideias foram sendo lançadas no sentido de apaziguar, talvez, uma grande angústia, 
representada pelo caráter etnocêntrico que marcou esses museus na Europa. Assim, a função educativa dos museus de etnologia tornou-se um tema recorrente, com a exploração da ideia de que esses museus poderiam ser um veículo de luta contra um nacionalismo extremado, ao proporcionar o 'contato com outras culturas não europeias'. Essa postura, entretanto, encontrava oponentes que acreditavam que os museus de etnologia acabariam sendo reduzidos a meros museus de arte não europeia, ao custo da perda de suas identidades como representantes do campo da ciência que dá suporte a eles (HARMS, 1990, p. 458).

\section{Objetos indígenas e patrimônio}

Segundo Vrdoljak (2008), o direito internacional instituído após a Segunda Guerra Mundial privilegiou como sujeitos o Estado e o indivíduo, comprometendo a proteção da identidade coletiva de grupos indígenas. Nesse sentido, no contexto de descolonização da segunda metade do século $\mathrm{XX}$, esses grupos, em campanhas para afirmar sua autodeterminação, reivindicavam não só o retorno de suas terras, como também o dos restos mortais de seus ancestrais e o de seu patrimônio cultural. As dificuldades em obtenção de reconhecimento internacional dessas demandas fizeram com que a restituição do patrimônio cultural se tornasse uma preocupação central para as organizações indígenas, pois assumia também o caráter de denúncia das políticas de esquecimento, empreendidas por certos Estados que, ao desenvolverem políticas de assimilação e de integração, deshistoricizaram e des-politizaram as diferenças entre povos indígenas e a cultura dominante.

Perante essas reivindicações, alguns museus de etnologia passaram a defender seu acervo, alegando a necessidade de exposições permanentes sobre variadas culturas, de forma a criar um sentimento de solidariedade com esses povos não europeus, reduzindo preconceitos. Os objetos, então, passaram a ser encarados como 'objetos discursivos' ou 'objetos retóricos', como sujeitos de campos semânticos que se modificam (STARN, 2005), que, em diversos momentos de suas exibições, são suscetíveis de uma construção multiforme de significados.

Se por um lado, essa perspectiva de construções narrativas sobre os objetos ampliava as possibilidades de ultrapassar a interpretação unívoca dos especialistas dos museus, por outro, gerava resistências por parte de organizações indígenas, que advogavam que os objetos, no caso os etnográficos, são suportes e testemunhos de valores passados e presentes, não somente significados e espécimes (STARN, 2005). Essa discussão apontava, então, para a perspectiva do patrimônio cultural, na qual a presunção de propriedade deveria estar presente.

Concomitantemente, as mudanças epistemológicas, ocorridas nos anos 1980, preconizavam que a produção do conhecimento realizada de forma cumulativa 
negligenciava o caráter inerentemente político de sua busca, realização e disposição. Era exigida então, uma maior reflexividade, por meio da qual se deveria atentar para os processos de produção e de disseminação do conhecimento, e levar em conta a natureza parcial, em duplo sentido, e posicional do próprio conhecimento (MAcDONALD, 2011). Questionava-se, assim, a maneira como os produtos culturais eram construídos e a crença na objetividade das estratégias utilizadas nesse processo que privilegiam certos tipos de conhecimento e marginalizam outros.

Os museus foram especialmente alvo dessa posição crítica voltada para políticas de identidade, no sentido de que ao selecionar bens culturais para guarda e posterior exposição, essas instituições, ao mesmo tempo em que reconhecem e afirmam identidades, omitem o reconhecimento e a afirmação de outras (MAcDONALD, 2011).

No caso dos objetos etnográficos, o tema que sobressaiu dessa discussão foi o da crise dos museus de etnologia, em função de sua constituição, no século XIX, como espaços de construção do conhecimento, em que os objetos e as coleções serviam como instrumentos empíricos para as teorias que eram produzidas, sendo esses objetos concebidos como testemunhos "para a verificação da prova - existência de antigas civilizações, de povos primitivos" (DIAS, 2007, p. 129). O afastamento dos antropólogos desses museus, em função da consolidação da antropologia como disciplina acadêmica, o que acabou enfatizando o trabalho de campo em detrimento do trabalho no museu, também acirrava a situação de crise desses museus.

A constituição da Nova Museologia, nos anos 1980, refletiu as mudanças teóricas e metodológicas que tiveram lugar no campo da museologia (MAcDONALD, 2011) ao voltar-se para a relevância da associação do museu ao patrimônio cultural e natural como pressupostos significativos para a identidade e para a memória das comunidades. Essas mudanças atingiram as práticas museológicas vigentes, bem como o ensino e as concepções sobre as funções dos museus, e se firmaram como o paradigma dominante nas orientações da museologia e do patrimônio cultural.

O crescimento significativo da quantidade de museus no Brasil, desde a década de 1980, e, entre eles, dos museus de antropologia e etnografia, foi também registrado em estudos do campo da antropologia e da museologia (NASCIMENTO JUNIOR, 2010).

Se ao longo do século XIX e até a metade do século XX, os museus representavam os índios, a partir da década de 1980 passam a surgir experiências nas quais os índios usam os museus, criando ou ressignificando acervos já constituídos: “algumas expressivas lideranças indígenas descobriram que museus são potencialmente 'explosivos' e podem contribuir para recuperar a memória perdida e reconstruir destruídas formas de vida" (FREIRE, 2003, p. 219). Em 1999, Freire escreveu um artigo, republicado em 2003, cujo título, 'Os índios descobrem os museus', é bastante indicativo da mudança operada nos museus de 
antropologia e etnografia. Nesse trabalho, Freire (2003) analisa seis experiências brasileiras que demonstram a inversão da fórmula, até então, empregada para a relação museus e índios. ${ }^{4}$

Tratamos aqui dos objetos indígenas, mas é necessário destacar outros tipos de museus de etnologia que acionam a noção de patrimônio cultural. Madariaga (2009) procura fornecer uma classificação para esses museus, definindo quatro modalidades: podem tratarse de museus locais, regionais ou nacionais; podem atender a demandas concretas, relacionadas com o tradicional, os fazeres domésticos, os aspectos religiosos etc.; podem corresponder também aos museus, cujos acervos foram formados em contextos colonialistas, que buscam mostrar a diversidade e as diferenças das culturas 'exóticas'; e, ainda, podem estar voltados para a apresentação dos diversos ruralismos, influenciados pelos movimentos folclóricos do Romantismo. A autora conclui afirmando que seriam poucos, entretanto, aqueles que propõem uma reflexão sobre os conflitos sociais e culturais; podem, inclusive, mostrar o objeto ou os objetos e para que servem, podem até contextualizá-los, mas não buscam apontar como influem socialmente (MADARIAGA, 2009, p.66).

\section{A patrimonialização de bens culturais de grupos indígenas}

Por fim, analisamos como os objetos indígenas foram tratados pela política federal do patrimônio cultural no Brasil, executada pelo Instituto do Patrimônio Histórico e Artístico Nacional. Apresentamos esse importante tema na conclusão deste artigo não no intuito de aprofundá-lo, mas com a intenção de trazê-lo à tona. $\mathrm{E}$ isso porque consideramos que a historicização de práticas sociais e seus significados - no nosso caso, do colecionamento dos objetos indígenas no contexto do colonialismo - deve conduzir à reflexão sobre os usos que estão sendo processados sobre o tema no presente (OLIVEIRA, 2007).

No Decreto-lei $\mathrm{n}^{\circ} 25$, que instituiu o instrumento de tombamento para a proteção de bens de natureza material pelo então Serviço do Patrimônio Histórico e Artístico Nacional ${ }^{5}$

\footnotetext{
${ }^{4}$ As seis experiências analisadas por Freire são: o Museu Magüta; a Exposição 'Memórias da Amazônia: Experiências de Identidade e Afirmação Étnica, ocorrida em Manaus; a Embaixada dos Povos da Floresta, que teve lugar na Casa do Sertanista, em São Paulo; a exposição itinerante Ciência Kayapó - Alternativas contra a Destruição, organizada pelo Museu Paraense Emílio Goeldi; o projeto então em andamento do Museu do Descobrimento; e o Museu do Índio de Brasília (FREIRE, 2003).

${ }^{5}$ O Instituto do Patrimônio Histórico e Artístico Nacional (IPHAN) foi criado pela Lei $\mathbf{n}^{\circ}$ 378, de janeiro de 1937, com o nome de Serviço do Patrimônio Histórico e Artístico Nacional (SPHAN). Ao longo de sua história recebeu outras denominações, como: Diretoria do Patrimônio Histórico e Artístico Nacional (DPHAN), de 1946 a 1970; Instituto do Patrimônio Histórico e Artístico Nacional (IPHAN), de 1970 a 1979; Secretaria do
} 
(Sphan), ambos de 1937, são designados quatro livros de Tombo para a inscrição de bens que passam a ser considerados patrimônio histórico e artístico nacional. No item 1, do artigo 4 do Decreto-lei é estipulado que devem ser inscritas no Livro do Tombo Arqueológico, Etnográfico e Paisagístico "as coisas pertencentes às categorias de arte arqueológica, etnográfica, ameríndia e popular"; portanto, somente um livro foi destinado a três diferentes atribuições de valor. ${ }^{6}$

Sabemos da grande influência do Anteprojeto de criação do Serviço do Patrimônio Artístico Nacional escrito por Mário de Andrade na formulação do Decreto-lei de 1937, embora nem todas as propostas do escritor tenham sido usadas. Mesmo assim, o Anteprojeto é importante porque especifica um pouco mais o entendimento sobre os objetos indígenas e seu lugar na futura instituição de proteção ao patrimônio nacional.

A categoria etnográfico associada aos objetos indígenas aparece em dois trechos do Anteprojeto. No primeiro deles, está relacionada às "artes arqueológica e ameríndia" - "que de alguma forma interessem à Arqueologia em geral e particularmente à arqueologia e etnografia ameríndias" (ANDRADE, 2002, p. 274) -, as quais se especificam em: "objetos (fetiches, instrumentos de caça, de pesca, de agricultura); objetos de uso doméstico; veículos, indumentárias etc., monumentos, paisagens e folclore ameríndio (vocabulários, cantos, lendas, medicina, culinária ameríndia etc.)" (ANDRADE, 2002, p. 274; grifo nosso). No segundo, foi associada à "arte popular", seguindo o roteiro anterior, do qual estaria excluída a "arte ameríndia". Mário de Andrade também concebeu o patrimônio artístico nacional como constituído por livros de Tombo e museus, de forma que a cada livro de tombamento corresponderia um museu. Além disso, propôs a presença de dois etnógrafos como membros de um futuro Conselho Consultivo.

Assim, já estava presente no Anteprojeto de Mario de Andrade a proposta de se constituir somente um livro do Tombo para as duas categorias - arqueologia e etnografia. No Decreto-lei $\mathbf{n}^{\circ} 25$ foi adicionado a esse Livro o termo "paisagístico", que, no Anteprojeto, já se encontrava associado àquelas duas categorias.

Podemos procurar os motivos para a previsão de somente um livro do Tombo para a arqueologia e a etnografia na própria condição da antropologia no Brasil naquele momento. Como vimos, essa conjunção entre arqueologia e etnografia fez parte da trajetória dos museus até o momento em que teve início o processo de autonomização da antropologia como disciplina e os objetos etnográficos passaram a ser explicitados não somente como documento, mas também como fonte da disciplina. No Brasil, os cursos superiores de

Patrimônio Histórico e Artístico Nacional e Fundação Nacional Pró-Memória (SPHAN/Pró-Memória), de 1979 a 1990, sendo que entre 1981 a 1985, tornou-se Subsecretaria; Instituto Brasileiro do Patrimônio Cultural (IBPC), de 1990 a 1994; e, a partir de então, IPHAN.

${ }^{6}$ Os outros livros do Tombo são: Livro de Belas Artes; Livro Histórico; Livro de Artes Aplicadas. 
antropologia na década de 1930 eram muito recentes por ocasião da criação do Sphan. Os espaços institucionais dos museus, compartilhados com a arqueologia, a antropologia física e a paleontologia, permaneciam ainda presentes no cotidiano da disciplina, pelo menos, até a década de 1960, quando foram criados os cursos de pós-graduação em antropologia nas universidades públicas, contribuindo para que a disciplina se estabelecesse como uma ciência social (PEIRANO, 1999). Nesse sentido a associação entre antropologia e arqueologia retratava as práticas dessas disciplinas realizadas no âmbito dos museus. ${ }^{7}$

A existência de somente um livro com tríplice inscrição dificulta o reconhecimento imediato da atribuição de valor etnográfico a um determinado bem. Para definir que valor foi conferido aos bens inscritos nesse livro, Ana Cristina Paiva (2012) trabalhou com processos de tombamento, entre 1938 e 2010, e identificou dezenove bens inscritos nessa categoria, classificando-os em quatro grupos: para o grupo "cultura popular" foram reconhecidos oito bens, como, por exemplo, o Estádio do Maracanã; sete bens foram relacionados à "cultura negra", principalmente os terreiros de candomblé; dois bens, a grupos de "imigrantes", como o Casarão do Chá ligado à imigração japonesa; e dois, a grupos de "elite", a Coleção Mario de Andrade e o Monumento aos Mortos da II Guerra Mundial (PAIVA, 2012, p. 64).

Podemos perceber que na relação não há nenhum bem de origem indígena. Uma das justificativas para tal ausência é normalmente associada ao fato desses bens se encontrarem em museus, de forma que a musealização já seria suficiente para sua proteção, não sendo necessária a aplicação do tombamento (CORRÊA, 2001).

Outro indício para a compreensão dessa ausência pode ser encontrado no artigo escrito, em 1937, pela então diretora do Museu Nacional, Heloisa Alberto Torres, na Revista do Serviço do Patrimônio Histórico e Artístico Nacional:

O simples fato de nos encontrarmos em face de gente que não consegue exprimir, ou sugerir sequer, o modo por que desejara ser amparada, que nem sempre é capaz de discernir o que convém lhe seja aplicado, deixa ao nosso inteiro arbítrio a decisão sobre o modo de proceder. Sem tirar da mente o nosso ponto de vista de civilizados - o que, me parece, nem corre risco de acontecer - seríamos obrigados a mergulhar profundamente, no tempo, de modo a nos colocarmos a nível capaz de julgar do maior interesse dessas populações, tão próximas de nós, no espaço (TORRES, 1937, p. 25).

\footnotetext{
${ }^{7}$ Como, por exemplo, o Museu Paraense Goeldi, o Museu Nacional e o Museu Paulista, cujo acervo foi transferido em 1989 para o Museu de Arqueologia e Etnologia da Universidade de São Paulo.
} 
A aplicação dos instrumentos oficiais disponíveis de preservação do patrimônio cultural não era vista como adequada ao caso indígena, pela incapacidade dos agentes estatais de entender o lugar dos objetos indígenas no panteão do patrimônio nacional. Como solução para o 'problema indígena', Torres afirmava que "a chave do problema de proteção aos indígenas reside - e isso está bem claro na consciência de quantos já refletiram no assunto - na demarcação de terras" (TORRES, 1937, p. 28), e que, portanto, era de competência de outro órgão estatal, o Serviço de Proteção aos Índios, o qual poderia "contar com um grande acervo de experiência [...] acumulado nos seus vinte anos de funcionamento e que, a cada instante, estará a ditar-lhe medidas mais adequadas de atividade" (TORRES, 1937, p. 29).

Como prenunciado pela diretora do Museu Nacional, em 1942, foi criada, no âmbito do Serviço de Proteção aos Índios, a Seção de Estudos, com o objetivo de documentar as culturas indígenas, "por meio de pesquisas etnográficas, levantamento linguístico e registros fotográficos, cinematográficos e sonoros, além de organizar os arquivos existentes" (COUTO, 2007, p. 181), visando a criar condições científicas para a proteção aos grupos indígenas. Em 1953, como já nos referimos, o antropólogo Darcy Ribeiro, que já havia sido contratado em 1947 pela Seção de Estudos, fundou o Museu do Índio, seguindo as concepções preconizadas pelo Museu do Homem: combate ao preconceito e ao racismo; exposição de artefatos que expressassem a riqueza estética das diversas culturas; e "ênfase nos aspectos de igualdade entre os povos e de pertencimento das etnias indígenas ao conjunto da humanidade do que propriamente em suas diferenças culturais." (ABREU, 2007, p. 148). ${ }^{8}$

Assim sendo, os espaços destinados aos objetos etnográficos indígenas no Brasil continuaram sendo os museus. De forma que, fora algumas ações voltadas para o inventário de objetos etnográficos pertencentes a coleções museológicas ${ }^{9}$, os grupos indígenas só aparecem tardiamente na política de preservação do Iphan, com a instituição em 2000 do Programa Nacional do Patrimônio Imaterial, que instituiu os livros de Registro.

Com a criação do instrumento de registro ${ }^{10}$ para a proteção a bens de natureza imaterial, não são mais objetos específicos o foco da preservação, mas processos que estão

\footnotetext{
${ }^{8}$ As concepções presentes na criação do Museu do Índio influenciaram outros museus, cujos acervos eram formados por objetos indígenas, como foi o caso do Museu das Culturas Dom Bosco, originário da missão Salesiana em Mato Grosso do Sul (THOMPSON, 2012).

${ }^{9}$ Em 1988, a Coordenadoria Geral de Acervos Museológicos da Sphan/Pró-Memória publicou o Dicionário do Artesanato Indígena, de autoria da antropóloga Berta Ribeiro, que foi resultado de um inventário realizado sobre objetos indígenas encontrados em museus etnográficos (RIBEIRO, 1988).

${ }^{10}$ Os bens são agrupados por categoria e registrados em livros, classificados em: Livro de Registro dos Saberes, para os conhecimentos e modos de fazer enraizados no cotidiano das comunidades; Livro de Registro de Celebrações, para os rituais e festas que marcam a vivência coletiva, religiosidade, entretenimento e outras práticas da vida social; Livro de Registros das Formas de Expressão, para as manifestações artísticas em geral; e Livro de Registro dos Lugares, para mercados, feiras, santuários, praças onde são concentradas ou reproduzidas práticas culturais coletivas (INSTITUTO DO PATRIMÔNIO HISTÓRICO E ARTÍSTICO NACIONAL, 2014).
} 
relacionados a formas de expressão, lugares, saberes e celebrações. ${ }^{11} \mathrm{O}$ objetivo da preservação não são os suportes físicos do bem,

[...] mas a busca de instrumentos e medidas de salvaguarda que viabilizem as condições de sua produção e reprodução, tais como: a documentação do bem, com vistas a preservar sua memória; a transmissão de conhecimentos e competências; o acesso às matérias primas e demais insumos necessários à sua produção; o apoio e fomento à produção e ao consumo; a sua valorização e difusão junto à sociedade; e, principalmente, esforços no sentido de que os detentores desses bens assumam a posição de protagonistas na preservação de seu patrimônio cultural (INSTITUTO DO PATRIMÔNIO HISTÓRICO E ARTÍSTICO NACIONAL, 2010, p. 18, grifo nosso).

Destacamos acima os termos salvaguarda e detentores. A salvaguarda, como definida acima, é a ação que a instituição exerce visando garantir a continuidade do processo cultural, que deve ser conduzido pelos próprios detentores dos bens preservados. A noção de detentores confere aos grupos e comunidades sua condição de representantes de suas próprias culturas.

O caso da cachoeira de Iauaretê, primeira inscrição no Livro de Registro dos Lugares, apresenta duas questões interessantes para essa discussão.

Em primeiro lugar, o processo de salvaguarda pode levar a demandas não previstas inicialmente. Embora as ações de preservação não estejam mais focando os objetos, é significativo que a noção de patrimônio cultural produza movimentos voltados para a restituição de bens que se encontram em museus, pois se baseia na ideia de propriedade.

É o caso da restituição aos povos do Alto Rio Negro de ornamentos sagrados (basá busá), que se encontravam no Museu do Índio, em Manaus, uma instituição salesiana. O processo foi iniciado em 2006 "como parte das atividades de salvaguarda da 'cachoeira de Iauaretê', registrada como patrimônio imaterial do Brasil pelo Iphan” (MARTINI, 2012, p. 332). Em 2008, as peças foram entregues à Federação das Organizações Indígenas do Rio Negro (FOIRN), em São Gabriel da Cachoeira.

\footnotetext{
${ }^{11}$ Os bens inscritos nos livros de Registro relativos a grupos indígenas são até o momento: Arte Kusiwa Pintura Corporal e Arte Gráfica Wajãpi; Cachoeirade Iauaretê - Lugar sagrado dos povos indígenas dos rios Uaupés e Papuri; Ritual Yaokwa do Povo Indígena Enawene Nawe; Saberes e Práticas Associados aos Modos de Fazer Bonecas Karajá; Sistema Agrícola Tradicional do Rio Negro, Rtixòkò: expressão artística e cosmológica do Povo Karajá (INSTITUTO DO PATRIMÔNIO HISTÓRICO E ARTÍSTICO NACIONAL, 2014).
} 
A segunda questão diz respeito à dicotomia material / imaterial. A despeito da discussão recorrente sobre se o patrimônio cultural é imaterial, pois se refere à transmissão e ao recebimento de memórias e conhecimentos e à atribuição de valores (SMITH, 2006), ou se qualquer imaterialidade necessita de suportes materiais para se realizar, como, por exemplo, o próprio corpo (MENESES, 2012), essa dicotomia se reproduz no processo administrativo da política pública de preservação que determina que instrumento, o tombamento ou o registro, deve ser aplicado a determinado bem. Como afirma Paiva (2012, p. 119),

[...] dentre os valores atribuídos aos patrimônios imateriais, o valor de lugar é o que potencialmente permite maior aproximação com o que no Iphan vem sendo classificado como patrimônio etnográfico [aquele cujos valores se referem ao Livro Arqueológico, Etnográfico e Paisagístico]. E isto devido à relevância de sua dimensão material, permitindo-nos visualizar, a um só tempo, o duplo material-imaterial que constitui todo bem cultural.

Essa discussão foi intensa no Conselho Consultivo do Iphan quando do registro da Cachoeira de Iauaretê. Alguns conselheiros, consideravam que o bem deveria ser tombado, pois seria o instrumento mais adequado para a proteção do espaço físico onde a prática cultural é realizada.

O conselheiro Ulpiano Bezerra Meneses observou que:

[...] a categoria que conta para eles não é imaterial, o mito é imaterial mas a cachoeira não é imaterial. [...] Portanto, acho que é caso de tombamento, que superaria o registro, porque ele absorve o registro também. Isto é uma coisa tão importante que precisa ser protegida implicando, portanto, em obrigações de fazer e não fazer, e não apenas o reconhecimento puramente moral de um valor cultural (CONSELHO CONSULTIVO DO PATRIMÔNIO CULTURAL, 2006, p. 47).

Outros conselheiros defendiam a importância do registro como o instrumento apropriado a manifestações culturais que não haviam sido historicamente contempladas pelo instrumento de tombamento.

A conselheira Maria Cecilia Londres Fonseca ponderou que:

Gostaria de observar que, na verdade, quando se pensa o registro, lembrando apenas o seu histórico, é no sentido de suprir uma lacuna, que o tombamento não preencheu, referente a uma série de bens reconhecidos ou considerados implicitamente como Patrimônio Cultural Brasileiro, ainda que não houvesse um rito, um instrumento 
que viabilizasse esse reconhecimento, do ponto de vista legal. Então o registro foi pensado exatamente para se adequar às especificidades dessas manifestações que estão expressas nos quatro livros (CONSELHO CONSULTIVO DO PATRIMÔNIO CULTURAL, 2006, p. 44).

\section{Conclusão}

Não somente os bens culturais, assim denominados, sofrem um processo de seleção e hierarquização no processo de patrimonialização, como são alvo também de disputas por sua classificação.

Os objetos indígenas foram musealizados a partir de lógicas colecionistas que retratavam práticas sociais, modos de conhecimento e relações de poder, que foram construídos e reconstruídos ao longo da história do colonialismo e do pós-colonialismo. Com a ampliação da noção de patrimônio cultural, também a concepção de etnografia se dilatou como método que extrapolou o âmbito da antropologia, sendo adotado por diversas disciplinas das ciências sociais. Da mesma forma, os objetos etnográficos passaram a qualificar não somente os testemunhos materiais e imateriais de uma cultura, mas tudo aquilo que traz diretamente ou indiretamente, aos olhos do etnólogo, a inscrição específica de um grupo humano, admitindo qualquer forma (LENCLUD, 2013, p. 475).

Hoje essas práticas e conhecimentos são reconstruídos em processos de patrimonialização de manifestações culturais, designadas por celebrações, saberes, lugares, formas de expressões, como explicitado pelo registro. Embora esse instrumento tenha vindo "suprir uma lacuna", ainda assim "[...] inclui a ideia de seleção, de construção de um acervo digno de ser memorializado em oposição a um outro conjunto de bens culturais que devem ser relegados ao esquecimento." (LIMA FILHO, ABREU, 2007, p. 35).

É importante que nos questionemos, portanto, se processos de patrimonialização, mediatizados pelo poder público, não acabam reproduzindo procedimentos que se inserem em novas práticas de colecionamento, ao selecionar, classificar e conservar bens culturais descolando-os de outros de mesma ordem.

\section{Bibliografia}

ABREU, Regina. Tal antropologia, qual museu? In: ABREU, Regina; CHAGAS, Mário de S.; SANTOS, Myrian S. (Org.). Museus, coleções e patrimônios: narrativas polifônicas. Rio de Janeiro: Garamond; MinC/IPHAN/DEMU, 2007. p.114-125. 
ALEXANDER, Edward P.; ALEXANDER, Mary. Museums in motions: an introduction to the history and functions of museums. 2. ed. New York: Altamira Press, 2008.

ANDRADE, Mário. Anteprojeto para a criação do Serviço do Patrimônio Artístico Nacional. Revista do Patrimônio Histórico e Artístico Nacional, Brasília, n. 30, p. 271-287, 2002.

BENNETT, Tony. The birth of the museum: history, theory, politics. London: Routledge, 2009.

BOURGUET, Marie-Noëlle. O explorador. In: VOVELLE, Michel. O homem do iluminismo. Lisboa: Editorial Presença, 1997. p. 207-250.

CAVIGNAC, Julie A. Museologia e etnografia: estudos americanistas no Brasil no início do século XX. In: ENCONTRO ANUAL DA ASSOCIAÇÃO NACIONAL DE PÓS-GRADUAÇÃO E PESQUISA EM CIÊNCIAS SOCIAIS COMUNICAÇÃO, 35., 2011, Caxambu. Comunicação... Caxambu, 2011.

CHAGAS, Mário. Há uma gota de sangue em cada museu: a ótica museológica de Mário de Andrade. Cadernos de Sociomuseologia, Lisboa, n. 13, 1998.

CHAPMAN, William R. Arranging ethnology: A. H. F. Pitt Rivers and the typological tradition. In: STOCKING JUNIOR, George W. Objects and others: essays on museums and material culture. Madison, Wisconsin: The University of Wisconsin Press, 1985. p. 15-48.

CONSELHO CONSULTIVO DO PATRIMÔNIO CULTURAL. Ata da $49^{a}$ Reunião realizada 3 ago 2006. Disponível em:

<http://portal.iphan.gov.br/baixaFcdAnexo.do;jsessionid=3AA6C07E9B65DCF81FAA08E6616 32F5C?id=2734>. Acesso em: 20 jun. 2014.

CORRÊA, Alexandre Fernandes. Vilas, parque, bairro e terreiros: novos patrimônios na cena das políticas culturais em São Paulo e São Luís. 2001. Tese (Doutorado em Ciências Sociais) Pontifícia Universidade Católica de São Paulo, São Paulo, 2001.

COUTO, Ione Helena P. A tradução do objeto do "outro". In: ABREU, Regina; CHAGAS, Mário de S.; SANTOS, Myrian S. (Org.). Museus, coleções e patrimônios: narrativas polifônicas. Rio de Janeiro: Garamond, 2007. p. 179-202.

CUNHA, Manuela C. Política indigenista no século XIX. In: _ _ _ _. (Org.). História dos índios no Brasil. 2. ed. São Paulo: Companhia das Letras; 1998. p. 133-154.

DACOSTA KAUFMANN, Thomas. From treasury to museum: the collections of the Austrian Habsburgs. In: Elsner, J. \& Cardinal, R. (Eds). The cultures of collecting. (4a. ed.). Londres: Reaktion Books Ltd, 1997. p. 117-154.

DESVALLEES, André; MAIRESSE, François (Dir.). Dictionnaire encyclopédique de muséologie. Paris: Armand Colin, 2011.

DIAS, Nélia. Antropologia e museus: que tipo de diálogo. In: ABREU, Regina; CHAGAS, Mário de S.; SANTOS, Myrian S. (Org.). Museus, coleções e patrimônios: narrativas polifônicas. Rio de Janeiro: Garamond; MinC/IPHAN/DEMU, 2007. p. 126-137. 
ERIKSEN, Thomas H.; NIELSEN, Finn S. História da antropologia. 3. ed. Petrópolis: Vozes, 2001.

FREIRE, José R. B. A descoberta dos museus pelos índios. In: CHAGAS, Mário; ABREU, Regina. (Org.). Memória e patrimônio: ensaios contemporâneos. Rio de Janeiro: DP\&A, 2003. p. 219-254.

GRUPIONI, Luiz D. B. Coleções e expedições vigiadas: os etnólogos no Conselho de Fiscalização das Expedições Artísticas e Científicas no Brasil. São Paulo: Hucitec; Anpocs, 1998.

HARMS, Volker. The aims of the museum for ethnology: debate in the German-speaking countries. Current Anthropology, Chicago, v. 31, n. 4, p. 457-463, 1990.

HEGER, Franz. Die archäologischen und ethnographischen Sammelungen aus Amerika im k. k. Naturhistorischen Hofmuseums in Wien. Festschrift zum 16. Internationalen Amerikanisten-Kongress in Wien, p. 1-72, 1908.

INSTITUTO DO PATRIMÔNIO HISTÓRICO E ARTÍSTICO NACIONAL - IPHAN. Bens registrados. Disponível em: <http://portal.iphan.gov.br/portal/montarPaginaSecao. do?id=17743\&sigla=Institucional\&retorno=paginaInstitucional >. Acesso em: 10 jun. 2014.

. Os sambas, as rodas, os bumbas, os meus e os bois: princípios, ações e resultados da política de salvaguarda do patrimônio cultural imaterial no Brasil, 2003-2010. 2. ed. Brasília: IPHAN, 2010.

KURY, Lorelai. O Brasil dos viajantes: viajantes e naturalistas do século XIX. IN: PEREIRA, Paulo R. (Org.). Brasiliana da Biblioteca Nacional: guia de fontes sobre o Brasil. Rio de Janeiro: Nova Fronteira, 2001. p. 59-77.

LENCLUD, B. Methode etnographique. In: BONTE, Pierre; IZARD, Michel (Dir.). Dictionaire de l'ethnologie et de l'anthropologie. 4. ed. Paris: Quadrige/PUF, 2013.

L'ESTOILE, Benoît de. O arquivo total da humanidade: utopia enciclopédica e divisão do trabalho na etnologia francesa. Horizontes antropológicos, Porto Alegre, n. 20, p. 265-302, 2003.

LÉVI-STRAUSS, Claude. Antropologia estrutural. Rio de Janeiro: Tempo Brasileiro, 1975.

LIMA FILHO, Manuel Ferreira; ABREU, Regina Maria do Rego Monteiro de. A antropologia e o patrimônio cultural no Brasil. In: LIMA FILHO, Manuel Ferreira; BELTRÃO, Jane Felipe; ECKERT, Cornelia (Org.). Antropologia e patrimônio cultural: diálogos e desafios contemporâneos. Blumenau: Nova Letra, 2007. p. 21-44.

LOPES, Maria M. O Brasil descobre a pesquisa científica: os museus e as ciências naturais no século XIX. São Paulo: Hucitec, 1997.

MAcDONALD, Sharon. Expanding museum studies: an introduction. In: . (Ed.). $A$ companion to museum studies. Malden: Blackwell, 2011. p. 1-12. 
MADARIAGA, Celeste J. de. La musealización del patrimonio etnológico. In: PARRILLA, José M. G.; LÓPEZ, José M. C. (Ed.). La musealización del patrimonio. Hueva: Universidade de Hueva, 2009. p. 65-76.

MARTINI, André. O retorno dos mortos: apontamentos sobre a repatriação de ornamentos de dança (basá busá) do Museu do Índio, em Manaus, para o rio Negro. Instituto Socioambiental. Revista de Antropologia. São Paulo, v. 55, n. 1, p. 331-355, 2012.

MENESES, Ulpiano Bezerra. O campo do patrimonio cultural: uma revisão de premissas. In: FÓRUM NACIONAL DO PATRIMÔNIO CULTURAL. Sistema Nacional de Patrimônio Cultural: desafíos, estratégias e experiências para uma nova gestão. 1., 2012, Ouro Preto. Anais... Brasília: IPHAN, 2012. p. 25-39.

NASCIMENTO JUNIOR, José. À guisa de apresentação: por um novo olhar da relação entre cultura e economia. In: 7-18. . (Org.). Economia de museus. Brasília: MinC; IBRAM, 2010. p.

OLIVEIRA, João P. O retrato de um menino Bororo: narrativas sobre o destino dos índios e o horizonte político dos museus, séculos XIX e XXI. Tempo, Niterói, v. 12, n.23, p. 85-111, jul./dez. 2007.

PAIVA, Ana Cristina de Souza Gonçalves. As dinâmicas das duas metades: tombamento e patrimônio etnográfico no IPHAN. 2012. Dissertação (Mestrado em Preservação do Patrimônio Cultural) - IPHAN, Rio de Janeiro, 2012.

PEIRANO, Mariza G. S. Antropologia no Brasil (alteridade contextualizada). In: MICELI, Sérgio (Org.). O que ler na ciência social brasileira. 1. Antropologia. São Paulo: Sumaré, 1999. p. 225-266.

PENNY, H. Glenn. Objects of culture: ethnology and ethnographic museums in imperial Germany. Londres: University of North Caroline Press, 2002.

POSSAS, Helga C. G. Classificar e ordenar: os gabinetes de curiosidades e a história natural. IN: FIGUEIREDO, B.G.; VIDAl, D. G. (Org.). Museus: dos gabinetes de curiosidades à museologia moderna. Belo Horizonte: Argvmentvm; Brasília: CNPq, 2005. p. 151-164.

PRATT, Mary Louise. Humboldt e a reinvenção da América. Estudos Históricos, Rio de Janeiro, v.4, n. 8, p. 151-165, 1991.

RIBEIRO, Berta G. Dicionário do artesanato indígena. Belo Horizonte: Itatiaia; São Paulo: Unesp, 1988.

ROQUE, Ricardo. Headhunting and colonialism: anthropology and the circulation of human skulls in the Portuguese empire, 1870-1930. Hampshire: Palgrave Macmillan, 2010.

SHELTON, Anthony A. Cabinets of transgression: renaissance collections and the incorporation of the New World. In: ELSNER, J.; CARDINAL, R. (Ed.). The cultures of collecting. 4. ed. Londres: Reaktion Books, 1997. p. 156-176. 
. Museums and anthropologies: practices and narratives. In: MACDONALD, S. A companion to museum studies. Malden: Blackwell, 2011. p. 64-80.

SMITH, Laurajane. Uses of heritage. New York: Routledge, 2006.

STARN, Randolph. A Historian's brief guide to new museum studies. The American Historical Review, New York, v. 110, n. 1, p. 69-98, Feb. 2005.

STURGE, Kate. The other on display: translation in the ethnographic museum. 2003. Disponível em: $<$ http://www.soas.ac.uk/literatures/satranslations/sturge.pdf $>$. Acesso em: 18 nov. 2010.

THOMAS, Nicholas. Licensed curiosity: Cook's Pacific voyages. In: ELSNER, J.; CARDINAL, R. (Ed.). The cultures of collecting. 4. ed. Londres: Reaktion Books, 1997. p. 116136.

THOMPSON, Analucia. A coleção Natterer: objetos indígenas brasileiros. 2012. Tese (Doutorado em Museologia) - Universidade Lusófona de Humanidades e Tecnologias, Lisboa, 2012.

TORRES, Heloisa Alberto. Contribuição para o estudo da proteção ao material arqueológico e etnográfico no Brasil. Revista do Serviço do Patrimônio Histórico e Artístico Nacional, Rio de Janeiro, n. 1, p. 9-30, 1937.

VRDOLJAK, Ana F. International law, museums and the return of cultural objects. Cambridge: Cambridge University Press, 2008. 